Fixed Point Theory, 18(2017), No. 2, 741-754

DOI 10.24193/fpt-ro.2017.2.60

http://www.math.ubbcluj.ro/ nodeacj/sfptcj.html

\title{
VECTOR EQUILIBRIUM PROBLEMS FOR MULTIFUNCTIONS IN TOPOLOGICAL SEMILATTICE SPACES
}

\author{
NGUYEN THE VINH* AND PHAM THI HOAI** \\ * Department of Mathematics, University of Transport and Communications \\ 3 Cau Giay Street, Hanoi, Vietnam \\ E-mail: thevinhbn@utc.edu.vn \\ ** School of Applied Mathematics and Informatics \\ Hanoi University of Science and Technology, Hanoi, Vietnam \\ E-mail: hoai.phamthi@hust.edu.vn \\ Dedicated to Professor Do Hong Tan on the occasion of his 80th birthday
}

\begin{abstract}
Let $K$ be a nonempty compact $\Delta$-convex subset of a topological semilattice with pathconnected intervals. In this paper, under new assumptions, we establish some existence theorems of $x \in K$ such that $\mathcal{F}(A) \cap V E P(f) \neq \emptyset$, where $\mathcal{F}(A)$ is the set of all fixed points of the multifunction $A: K \rightarrow 2^{K}$ and $\operatorname{VEP}(f)$ is the set of all solutions for the vector equilibrium problems of the multifunction $f$ from $K \times K$ to a topological vector space $Y$. These results generalize and improve the recent ones in the literature. Some examples are given to illustrate our results.

Key Words and Phrases: KKM lemma, Ky Fan inequality, Browder-Fan fixed point theorem, multifunction, topological semilattice, $C_{\Delta}$-quasiconvex (quasiconcave), $C$-upper (lower) semicontinuous, vector equilibrium problem.

2010 Mathematics Subject Classification: 47H10, 47J20, 49J40.
\end{abstract}

Acknowledgments. This research was partially supported by UTC under Grant No. T2017- KHCB-60.

\section{REFERENCES}

[1] G. Allen, Variational inequalities, complementarity problems, and duality theorems, J. Math. Anal. Appl., 58(1977), 1-10.

[2] J.P. Aubin, I. Ekeland, Applied Nonlinear Analysis, John Wiley, New York, 1984.

[3] E. Blum, W. Oettli, From optimization and variational inequalities to equilibrium problems, Math. Student, 63(1994), 123-145.

[4] S.S. Chang, Y. Zhang, Generalized KKM theorem and variational inequalities, J. Math. Anal. Appl., 159(1991), 208-223.

[5] X.P. Ding, K.K. Tan, A minimax inequality with applications to existence of equilibrium point and fixed point theorems, Colloq. Math., 63(1992), 233-247. 
[6] K. Fan, A minimax inequality and applications, In: Inequalities, III (Proc. Third Sympos., Univ. California, Los Angeles, Calif., 1969; Dedicated to the memory of Theodore S. Motzkin, O. Shisha- Ed.), Academic Press, New York, 1972, 103-113.

[7] P.G. Georgiev, T. Tanaka, Fan's inequality for set-valued maps, Nonlinear Anal., 47(2001), 607-618.

[8] F. Giannessi, Vector Variational Inequalities and Vector Equilibria, Mathematical Theories, Nonconvex Optimization and its Applications, 38, Kluwer Academic Publ., Dordrecht, 2000.

[9] N. Hadjisavvas, S. Komlósi, S. Schaible, Handbook of Generalized Convexity and Generalized Monotonicity, Nonconvex Optimization and its Applications, Springer-Verlag, New York, 2005.

[10] S. Al-Homidan, Q.H. Ansari, Fixed point theorems on product topological semilattice spaces, generalized abstract economies and systems of generalized vector quasi-equilibrium problems, Taiwanese J. Math., 15(2011), 307-330.

[11] S. Al-Homidan, Q.H. Ansari, J.C. Yao, Collectively fixed point and maximal element theorems in topological semilattice spaces, Appl. Anal., 90(2011), 865-888.

[12] C.D. Horvath, Contractibility and generalized convexity, J. Math. Anal. Appl., 156(1991), 341357.

[13] C.D. Horvath, J.V. Llinares Ciscar, Maximal elements and fixed points for binary relations on topological ordered spaces, J. Math. Econom., 25(1996), 291-306.

[14] D.T. Luc, Theory of Vector Optimization, Lecture Notes in Economics and Mathematical Systems, 319, Springer-Verlag, Berlin, 1989.

[15] Q. Luo, KKM and Nash equilibria type theorems in topological ordered spaces, J. Math. Anal. Appl., 264(2001), 262-269.

[16] Q. Luo, The applications of the Fan-Browder fixed point theorem in topological ordered spaces, Appl. Math. Lett., 19(2006), 1265-1271.

[17] P.H. Sach, New nonlinear scalarization functions and applications, Nonlinear Anal., 75(2012), 2281-2292

[18] Q.Q. Song, L.S. Wang, The existence of solutions for the system of vector quasi-equilibrium problems in topological order spaces, Comput. Math. Appl., 62(2011), 1979-1983.

[19] Q.Q. Song, The existence and stability of solutions for vector quasiequilibrium problems in topological order spaces, J. Appl. Math., 2013, Art. ID 218402, 6 pp.

[20] G. Tian, Generalized KKM theorems, minimax inequalities, and their applications, J. Optim. Theory Appl., 83(1994), 375-389.

[21] N.T. Vinh, Matching theorems, fixed point theorems and minimax inequalities in topological ordered spaces, Acta Math. Vietnam., 30(2005), 211-224.

[22] N.T. Vinh, Some generalized quasi-Ky Fan inequalities in topological ordered spaces, Vietnam J. Math., 36(2008), 437-449.

[23] N.T. Vinh, Systems of generalized quasi-Ky Fan inequalities and Nash equilibrium points with set-valued maps in topological semilattices, Panamer. Math. J., 19(2009), 79-92.

[24] N.T. Vinh, P.T. Hoai, Ky Fan's inequalities for vector-valued multifunctions in topological ordered spaces, Fixed Point Theory, 15(2014), 253-264

[25] C.L. Yen, A minimax inequality and its applications to variational inequalities, Pacific J. Math., 97(1981), 477-481

[26] X.Z. Yuan, Knaster-Kuratowski-Mazurkiewicz theorem, Ky Fan minimax inequalities and fixed point theorems, Nonlinear World, 2(1995), 131-169.

[27] J. Zhou, G. Chen, Diagonal convexity conditions for problems in convex analysis and quasivariational inequalities, J. Math. Anal. Appl., 132(1988), 213-225.

Received: January 19, 2015; Accepted: October 10, 2015. 
